\title{
On the Mechanism of Methane Conversion in the Noncatalytic Processes of Its Thermal Pyrolysis and Steam and Carbon Dioxide Reforming
}

\author{
E. Busillo ${ }^{a}$, V. I. Savchenko ${ }^{b}$, and V. S. Arutyunov ${ }^{a, b, c, *}$ \\ ${ }^{a}$ Gubkin Russian State University of Oil and Gas (National Research University), Moscow, 119991 Russia \\ ${ }^{b}$ Institute of Problems of Chemical Physics, Russian Academy of Sciences, Chernogolovka, 142432 Russia \\ ${ }^{c}$ N.N. Semenov Federal Research Center for Chemical Physics, Russian Academy of Sciences, Moscow, 119991 Russia \\ *e-mail: v_arutyunov@mail.ru
}

Received June 23, 2021; revised July 30, 2021; accepted September 10, 2021

\begin{abstract}
A detailed kinetic modeling of the noncatalytic processes of thermal pyrolysis and steam and carbon dioxide reforming of methane revealed almost completely identical kinetics of the methane conversion in these processes. This suggests that, in the temperature range 1400-1800 K, the initial stage of conversion of methane in all these processes is its thermal pyrolysis. The modeling results agree well with the experimental data on methane pyrolysis. For the temperature range examined, the Arrhenius expressions (pre-exponential factors and activation energy) were obtained in the first-order kinetics approximation for the rate of methane conversion in the processes studied. The expressions derived may be useful for making preliminary estimates and carrying out engineering calculations.
\end{abstract}

Keywords: natural gas, methane, syngas, pyrolysis, steam reforming, carbon dioxide reforming

DOI: $10.1134 / \mathrm{S} 0965544121110037$

Natural gas, including its unconventional resources such as, above all, shale gas and methane hydrates, is the major hydrocarbon feedstock for the world economy $[1,2]$, which necessitates improving the efficiency of its conversion to most-demanded chemicals and motor fuels. Modern large-scale processes of chemical conversion of natural gas are based on its pyrolysis and conversion to syngas [3]. Apart from the conventional process of catalytic steam reforming of natural gas to produce syngas $[4,5]$, since recently there has been a growing interest in alternative syngas production routes such as Autothermal Reforming (ATR) [6], oxidative pyrolysis yielding not only syngas but also acetylene [7], and noncatalytic oxidation processes such as filtration combustion $[8,9]$ and matrix conversion $[10,11]$. Alongside partial oxidation of methane proper, essential stages of all these gas-phase processes are pyrolysis of methane and its interaction with the oxidative conversion products, water vapor and carbon dioxide:

$$
\mathrm{CH}_{4} \rightarrow \text { Products, }
$$

$$
\begin{aligned}
& \mathrm{CH}_{4}+\mathrm{H}_{2} \mathrm{O} \rightarrow 3 \mathrm{H}_{2}+\mathrm{CO}, \\
& \mathrm{CH}_{4}+\mathrm{CO}_{2} \rightarrow 2 \mathrm{H}_{2}+2 \mathrm{CO} .
\end{aligned}
$$

In recent years, the kinetics and thermodynamics of the catalytic processes of steam and carbon dioxide reforming of methane have become the focus of numerous studies (see, e.g., $[12,13])$. As to noncatalytic processes of steam and carbon dioxide reforming of methane, they have received much less research attention. At least, we could not find meaningful works on the kinetics of these processes in the range of conditions considered. Earlier, we carried out the kinetic analysis of steam reforming [14] and carbon dioxide reforming [15] of methane and showed that, in both cases, the methane conversion and hydrogen formation began at a much earlier point of time than the conversion of $\mathrm{H}_{2} \mathrm{O}$ and $\mathrm{CO}_{2}$, respectively (Fig. 1).

Based on the kinetic analysis of these processes, we made an assumption that, in the temperature range 1400 $1800 \mathrm{~K}$, despite the presence of $\mathrm{H}_{2} \mathrm{O}$ and $\mathrm{CO}_{2}$, the initial stage of methane conversion is thermal pyrolysis leading 
to the formation of hydrogen, ethylene, and acetylene. The latter, owing to its thermodynamic stability in the temperature range of interest, is the main hydrocarbon product of methane pyrolysis, yielded in significant concentrations by steam reforming and carbon dioxide reforming. Noticeable conversion of water vapor and carbon dioxide began only after appearance of acetylene among the reaction products (Fig. 1) and resulted from their interaction with the $\mathrm{H}^{*}$ atoms yielded by methane pyrolysis and the subsequent reaction of $\mathrm{OH}^{*}$ radicals with acetylene [15].

A strong evidence for this mechanism of noncatalytic processes of steam and carbon dioxide reforming of methane could be provided by comparison of the rates of methane conversion in these processes and in thermal pyrolysis of methane under the conditions of interest. To this end, a detailed kinetic modeling of the processes under consideration at a pressure of $1 \mathrm{~atm}$ was conducted in this study. Also, Arrhenius expressions for the rates of methane conversion in these processes over the temperature range considered were derived. They may be useful for making preliminary estimates and carrying out engineering calculations.

\section{EXPERIMENTAL}

For analyzing the kinetics of the processes considered and deriving the Arrhenius expressions to describe the corresponding methane conversion rates, kinetic modeling of these processes at a pressure of $1 \mathrm{~atm}$ in the temperature range $1400-1800 \mathrm{~K}$ at $100 \mathrm{~K}$ intervals was carried out. Modeling was based on the detailed kinetic mechanism AramcoMech3.0 [16] which had proved efficient under the conditions indicated; standard ANSYS Chemkin-Pro software was used.

To obtain the Arrhenius expressions for the rate of methane conversion in each of the processes considered, detailed calculation of the process kinetics at each specific temperature was performed in order to select the expression most adequately describing the methane conversion. The selection was based on the equation for the rate constant under assumption of first-order kinetics, which is valid for methane conversion under the actual conditions [17-19]. Using the Curve Fitting Toolbox package of the MATLAB software, fitting of the kinetics of the changes in the methane concentration obtained on the basis of the detailed kinetic mechanism was carried out using the power-law rate model. The trust-region least-squares algorithm was employed for the selection.

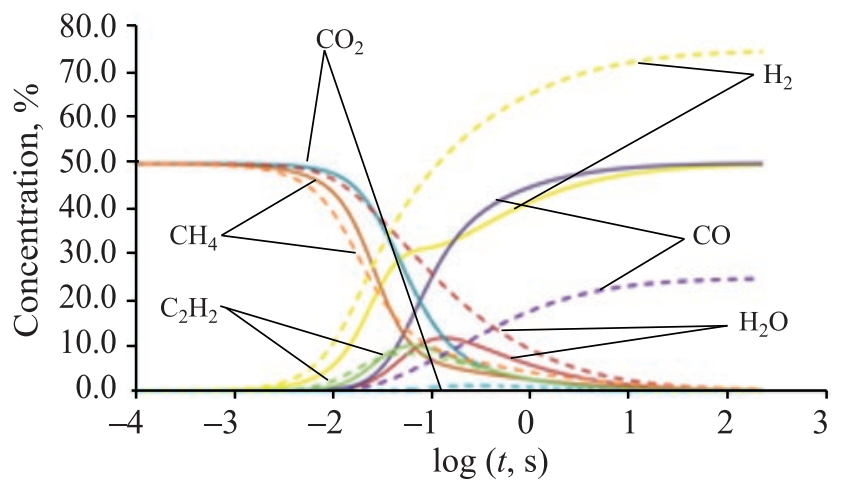

Fig. 1. Calculated kinetics of (solid lines) carbon dioxide and (dotted lines) steam reforming of methane under isothermal conditions at $\mathrm{CH}_{4} / \mathrm{CO}_{2}=1: 1$ and $\mathrm{CH}_{4} / \mathrm{H}_{2} \mathrm{O}=1: 1$, respectively. $T=1600 \mathrm{~K}$ [15].

Only modeling results for $20-70 \%$ methane conversions were involved in fitting, because simple first-order kinetics is unsuitable for describing the initial and final stages of the complex radical processes considered.

The expressions for the rate constants of the methane conversion in the range 1400-1800 K, yielded by fitting, were used for calculating the effective activation energy $E_{\text {eff }}$ and the pre-exponential factor $k_{0}$ for each process under study as the slope of the Arrhenius plot multiplied by the gas constant $R$ and the intercept on the $y$ axis, respectively:

$$
\ln k=\ln k_{0}-E_{\text {eff }} / R T,
$$

where $k$ is the rate constant, $\mathrm{s}^{-1} ; k_{0}$, pre-exponential factor, $\mathrm{s}^{-1} ; R$, universal gas constant $\left(R=8.314 \mathrm{~J} \mathrm{~mol}^{-1} \mathrm{~K}^{-1}\right)$; and $T$, temperature, $\mathrm{K}$.

\section{RESULTS AND DISCUSSION}

\section{Modeling the methane conversion processes.} Previously [14, 15], we made an assumption that steam reforming and carbon dioxide reforming of methane proceed via its preliminary thermal pyrolysis to acetylene, which conclusion was further extended to incorporate higher homologs of methane $[15,20]$. For validation of this conclusion, we compared in this study the kinetics of conversion of methane in the processes of steam and carbon dioxide reforming with that of its conversion in thermal pyrolysis. The plots in Fig. 2 present the calculated dependences of the changes in the concentration of the reactants and the products for pyrolysis, steam reforming, and carbon dioxide reforming of methane. Comparison 
(a)

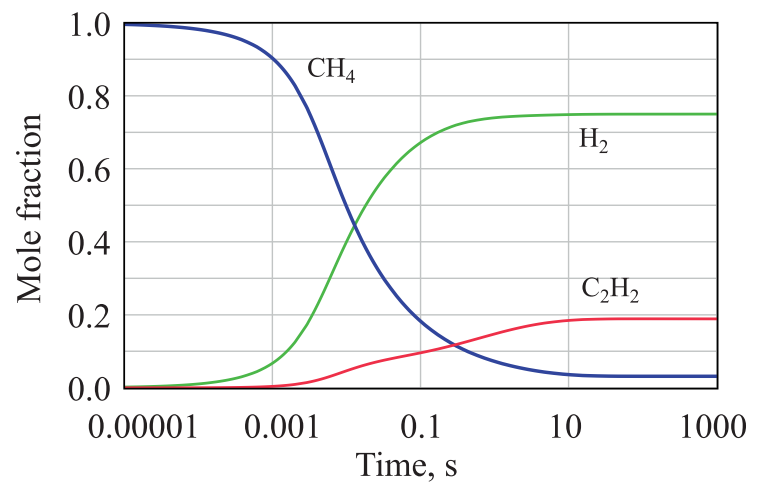

(b)

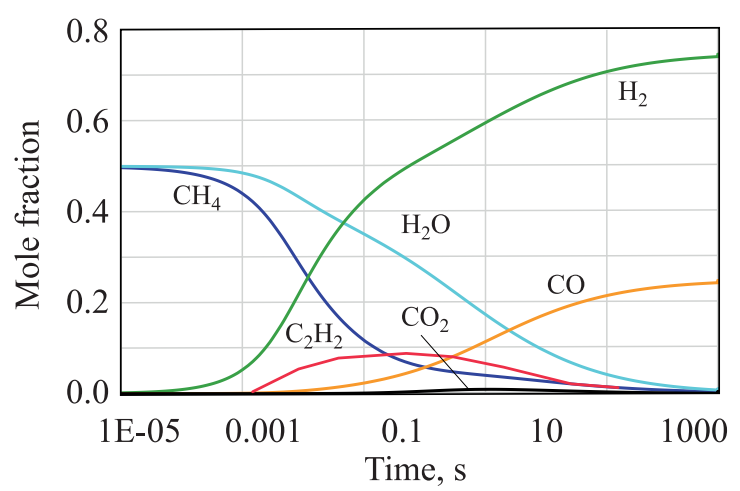

(c)

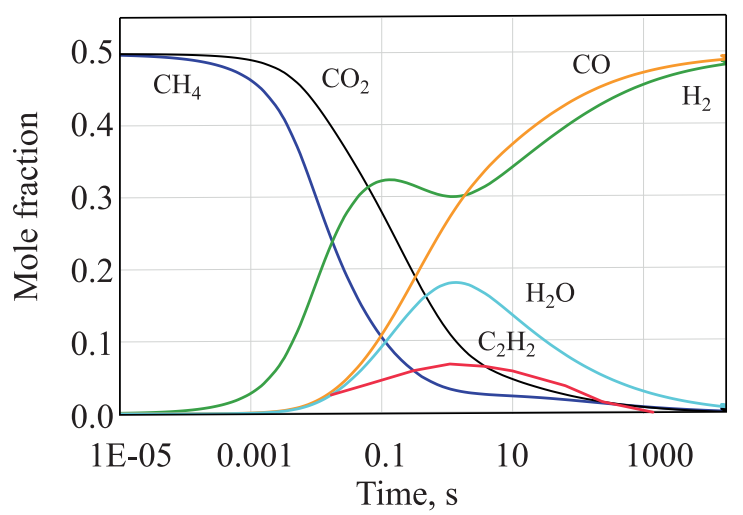

Fig. 2. Kinetics of the changes in the mole fractions of the reactants and the products in (a) pyrolysis, (b) steam reforming, and (c) carbon dioxide reforming of methane. Calculation is based on the AramcoMech 3.0 mechanism. $T=1700 \mathrm{~K}, P=1 \mathrm{~atm}$.

of these plots shows that in all the cases the methane conversion proceeded in a very similar way and over the same time, as more clearly demonstrated by Fig. 3, and acetylene was the main product accumulating in the initial stage alongside hydrogen.

In steam reforming and carbon dioxide reforming of methane the changes in the water and carbon dioxide

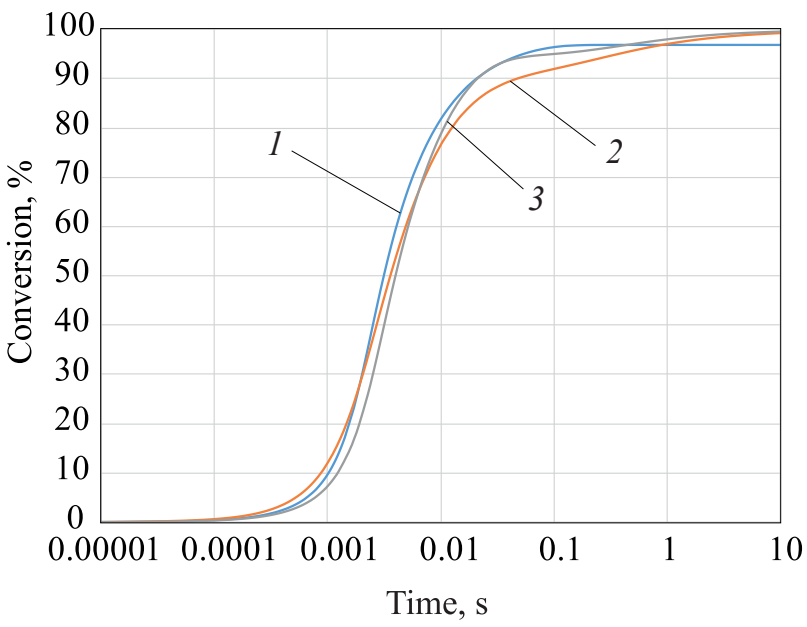

Fig. 3. Methane conversion in (1) pyrolysis, (2) steam reforming, and (3) carbon dioxide reforming. Calculation is based on the AramcoMech 3.0 model. $T=1700 \mathrm{~K}, \mathrm{P}=1 \mathrm{~atm}$.

concentration, respectively, lagged noticeably behind the change in the methane concentration. In the case of carbon dioxide reforming of methane the hydrogen resulted from methane pyrolysis entered into the reverse water-gas shift reaction:

$$
\mathrm{H}_{2}+\mathrm{CO}_{2} \rightarrow \mathrm{CO}+\mathrm{H}_{2} \mathrm{O},
$$

which caused an increase in the water vapor concentration. However, due to the presence of unreacted methane in the system, as well to the proceeding of the forward watergas shift reaction

$$
\mathrm{CO}+\mathrm{H}_{2} \mathrm{O} \rightarrow \mathrm{H}_{2}+\mathrm{CO}_{2}
$$

the water vapor concentration passed through a maximum and then quickly dropped almost to zero.

Results from comparison of the studied methane conversion processes for all the temperatures within the $1400-1800 \mathrm{~K}$ range were similar to those presented in Fig. 3. Comparison of the methane conversion kinetics in the three processes of interest (Fig. 3) unambiguously shows their identity, with only minor alterations introduced by the presence of water vapor and carbon dioxide.

Deriving the approximating expressions for the methane conversion rate constants. Published data on methane pyrolysis in the range of conditions under consideration [17-19] suggest the possibility of their approximation on the basis of the first-order reaction equation. This conclusion was based on the following 
evidence. As follows from our previous studies [14, 20], in the presence of $\mathrm{H}_{2} \mathrm{O}$ and $\mathrm{CO}_{2}$, the methane conversion is independent of their concentration. This immediately follows from the fact that steam reforming and carbon dioxide reforming do not proceed via direct interaction of methane with $\mathrm{H}_{2} \mathrm{O}$ or $\mathrm{CO}_{2}$; rather, the latter interact with the products of thermal pyrolysis of methane, for which processes the methane conversion can be approximated by the first-order reaction equation as well.

To obtain the approximating equations for describing the temperature dependence of the rates of the studied methane conversion processes in the temperature range $1400-1800 \mathrm{~K}$ at $P=1 \mathrm{~atm}$, fitting of the detailed modeling results on the basis of the Arrhenius temperature dependence equation was carried out. Figure 4 shows examples of such fitting for all the three processes at $T=1700 \mathrm{~K}$. As already mentioned, only the modeling results for conversions ranging from 20 to $70 \%$ were involved in fitting, because the initial and final stages of these complex radical processes cannot be described by simple first-order kinetics.

As seen from Fig. 4, approximation based on power-law rate model fitting fairly adequately describes the processes of interest. Using the approximating function parameters obtained for each temperature under the assumption of first-order kinetics, the Arrhenius expressions for the rate of the processes studied (activation energy in $\mathrm{J} / \mathrm{mol}$ ) were obtained:

$$
\begin{gathered}
\mathrm{CH}_{4} \rightarrow \text { products; } \\
k_{1}=1.73 \times 10^{13} \exp (-354200 / R T), \mathrm{s}^{-1}, \\
\mathrm{CH}_{4}\left(+\mathrm{H}_{2} \mathrm{O}\right) \rightarrow 3 \mathrm{H}_{2}+\mathrm{CO} ; \\
k_{2}=1.88 \times 10^{13} \exp (-358300 / R T), \mathrm{s}^{-1}, \\
\mathrm{CH}_{4}\left(+\mathrm{CO}_{2}\right) \rightarrow 2 \mathrm{H}_{2}+2 \mathrm{CO} ; \\
k_{3}=0.90 \times 10^{13} \exp (-348200 / R T), \mathrm{s}^{-1} .
\end{gathered}
$$

Methane conversion in all the cases proceeds as a formally unimolecular reaction whose rate in the presence of the second reactant is independent of the concentration of the latter. So, the second reactant was parenthesized and only denoted a specific process and the balance of the products formed thereby.

The expressions yielded by fitting of the kinetic modeling results can be compared with the expression obtained for the rate constant of methane pyrolysis via analysis of a large body of experimental data for the temperature range $1100-1700 \mathrm{~K}$ in $[18,19]$ : (a)

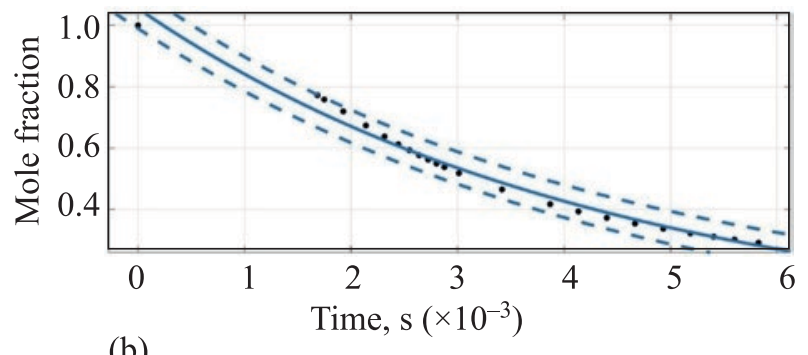

(b)

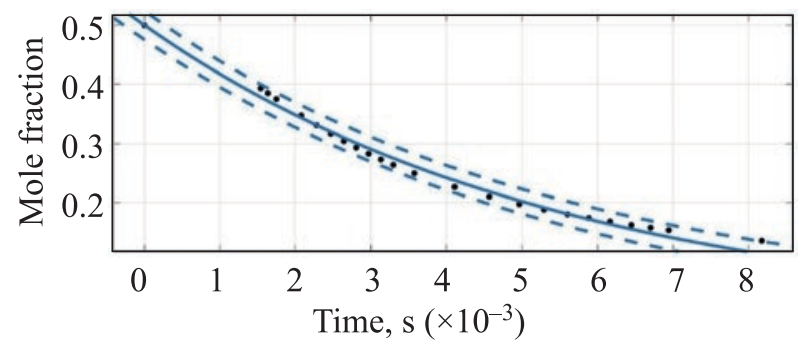

(c)

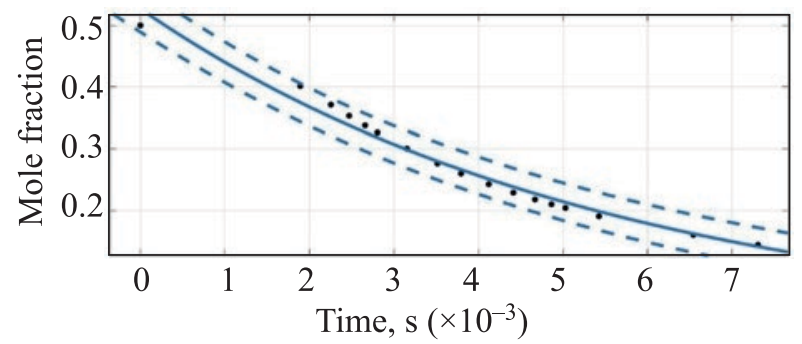

Fig. 4. Kinetics of the change in the mole fraction of methane in case of modeling of the processes of (a) pyrolysis, (b) steam reforming, and (c) carbon dioxide reforming of methane. $T=1700 \mathrm{~K}, P=1 \mathrm{~atm}$. (Symbols) Data calculated with AramcoMech 3.0 mechanism, (solid line) approximating curve, and (dashed lines) confidence limits (95\%) of the approximating function.

$$
\begin{gathered}
\mathrm{CH}_{4} \rightarrow \text { products; } \\
k_{1}=(0.3 \pm 0.1) \times 10^{13} \exp [-(343100 \pm 12600) / R T], \mathrm{s}^{-1} .
\end{gathered}
$$

In a similar way, fitting of the results of the detailed kinetic modeling in the first-order kinetics approximation, which is also valid in the case of steam conversion of methane, gave the following expression for the rate of $\mathrm{H}_{2} \mathrm{O}$ vapor conversion:

$$
k_{\mathrm{H}_{2} \mathrm{O}}=0.12 \times 10^{13} \exp (-362120 / R T), \mathrm{s}^{-1} .
$$

The expression obtained for the rate constant of the first-order reaction of $\mathrm{CO}_{2}$ conversion in the process of carbon dioxide reforming of methane appears as:

$$
k_{\mathrm{CO}_{2}}=0.14 \times 10^{13} \exp (-339720 / R T), \mathrm{s}^{-1} .
$$




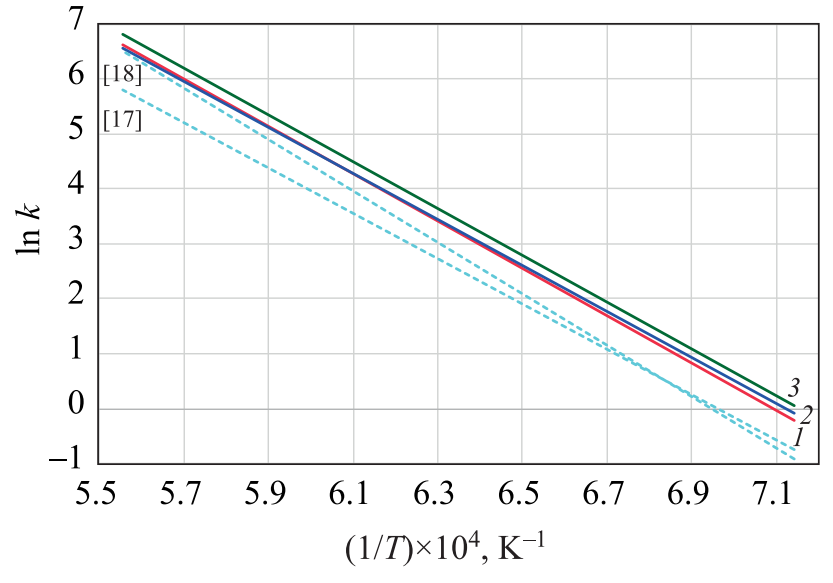

Fig. 5. Comparison of (solid lines) temperature dependences of the methane conversion rate constant obtained via kinetic modeling for (1) steam reforming, (2) pyrolysis, and (3) carbon dioxide reforming with (dashed lines) experimental temperature dependence of the methane pyrolysis rate constants from $[17,18]$.

The rate constants obtained for the conversion of the both reactants in the corresponding processes are very close. It is noteworthy, however, that, while the preexponential factors are practically identical, the effective activation energy for carbon dioxide conversion is slightly lower compared to that of water vapor conversion, despite a more favorable thermochemistry of steam reforming compared to carbon dioxide reforming of methane. This is also attributable to the lack of direct interaction of $\mathrm{H}_{2} \mathrm{O}$ and $\mathrm{CO}_{2}$ molecules with methane, which may well be the case for such a complex kinetic system.

The plots in Fig. 5 present the Arrhenius expressions for the rate constants of all the three studied methane conversion processes, yielded by kinetic modeling. They practically coincide with each other and within the accuracy of determination are in a fairly good agreement with the experimental data on methane pyrolysis in this temperature range.

Obviously, the effective activation energies obtained by kinetic modeling are almost equal for all the three methane conversion processes. A slight, at a $\sim 4 \mathrm{~kJ} / \mathrm{mol}$ level, difference is most likely associated with certain arbitrariness in selection of the specific approximating expressions for describing the calculated results and is hardly interpretable as really meaningful. Thus, our results may be considered as a kinetic evidence validating the assumption made in $[14,15]$ that, in the temperature range $1400-1800 \mathrm{~K}$, all the studied methane conversion processes involve the thermal pyrolysis stage.

In all the cases considered, the effective activation energy for methane conversion is significantly, by almost $100 \mathrm{~kJ} / \mathrm{mol}$, lower than the first $\mathrm{C}-\mathrm{H}$ bond dissociation energy $E_{\mathrm{CH}_{3}-\mathrm{H}}=432.4 \mathrm{~kJ} / \mathrm{mol}$ for the methane molecule [21]. This difference is most likely due in a large part to the radical-chain mechanism of the methane pyrolysis under the actual conditions, leading to its selfacceleration, which affects the effective activation energy. The accelerating effect produced on methane pyrolysis by products such as acetylene and ethylene was demonstrated experimentally [17].

A lower activation energy determined for methane pyrolysis in the experimental studies is only natural due to the following reasons:

- presence in the real gas of impurities such as heavier hydrocarbons for which the activation energies of pyrolysis are much lower and

- contribution coming to the experimental results from heterogeneous processes, characterized by significantly lower activation energies, that occur on the surface of the laboratory reactors which typically have small dimensions and, accordingly, high surface area-tovolume ratios.

Possible reason for a slightly lower experimental rate of methane pyrolysis is a decrease in the methane conversion rate because of involvement of a part of active radicals into formation of heavier products and soot, which are not taken into account by the kinetic model used in this study.

Thus, kinetic modeling of the studied methane conversion processes provided a convincing evidence for a single mechanism operating in their initial stage as controlled by the methane pyrolysis process.

\section{CONCLUSIONS}

Comparison of the results from the detailed kinetic modeling of the processes of thermal pyrolysis, steam reforming, and carbon dioxide reforming of methane revealed almost complete identity of the methane conversion kinetics in all these processes. This finding provides evidence that, in the temperature range 1400$1800 \mathrm{~K}$, the initial stage of conversion of methane consists in its thermal pyrolysis which is weakly affected by the presence of $\mathrm{H}_{2} \mathrm{O}$ and $\mathrm{CO}_{2}$. The results obtained are in a 
good agreement with the experimental data on methane pyrolysis. The Arrhenius expressions derived for the rate of methane conversion in these processes over the temperature range of interest may be useful for making preliminary estimates and carrying out engineering calculations as part of natural gas processing activities.

\section{AUTHOR INFORMATION}

E. Busillo, ORCID: https://orcid.org/0000-0002-3456-0351

V.I. Savchenko, ORCID: https://orcid.org/0000-00019823-6844

V.S. Arutyunov, ORCID https://orcid.org/0000-0003-03390297

\section{ACKNOWLEDGMENTS}

This study was carried out within the framework of the Basic Research Program of the State Academies of Sciences [Institute of Problems of Chemical Physics, Russian Academy of Sciences, theme no. 0089-2019-0018 (State registration no. AAA-A19-119022690098-3), N.N. Semenov Federal Research Center for Chemical Physics, Russian Academy of Sciences, theme no. 0082-2019-0014 (State registration no. AAAA-A20-120020590084-9)].

\section{OPEN ACCESS}

This article is distributed under the terms of the Creative Commons Attribution 4.0 International License (http:// creativecommons.org/licenses/by/4.0/), which permits unrestricted use, distribution, and reproduction in any medium, provided you give appropriate credit to the original author(s) and the source, provide a link to the Creative Commons license, and indicate if changes were made.

\section{REFERENCES}

1. BP Energy Outlook 2035: February 2015.

http://www.bp.com/energyoutlook (Accessed March 10, 2021).

2. Arutyunov, V.S. and Lisichkin, G.V., Chem. Rev., 2017, vol. 86, no. 8, pp. 777-804. https://doi.org/10.1070/RCR4723

3. Savchenko, V.I., Makaryan, I.A., and Arutyunov, V.S., Mir Nefteprodukt. Vestn. Neft. Komp., 2013, no. 11, pp. 3-12.

4. Rostrup-Nielsen, J.R., Catal. Today, 2002, vol. 71, pp. 243-247.

https://doi.org/10.1016/S0920-5861(01)00454-0

5. Makhlin, V.A. and Tsetseruk, Ya.R., Khim. Prom-st' Segodnya, 2010, no. 3, pp. 6-17.

6. Dybkjær, I. and Aasberg-Petersen, K., Can. J. Chem. Eng., 2016, vol. 94, pp. 607-612. https://doi.org/10.1002/cjce.22453

7. Zhang, Q., Wang, J., and Wang, T., Ind. Eng. Chem. Res., 2016, vol. 55, no. 30, pp. 8383-8394.

https://doi.org/10.1021/acs.iecr.6b00817

8. Kostenko, S.S., Ivanova, A.N., Karnaukh, A.A., and Polianczyk, E.V., Chem. Eng. Proc. Proc. Intens., 2017, vol. 122, pp. 473-486.

https://doi.org/10.1016/j.cep.2017.05.014

9. Fierro, M., Requena, P., Salgansky, E., and Toledo, M., Chem. Eng. J., 2021, vol. 425, p. 130178. https://doi.org/10.1016/j.cej.2021.130178

10. Arutyunov, V.S., Shmelev, V.M., Rakhmetov, A.N., and Shapovalova, O.V., Ind. Eng. Chem. Res., 2014, vol. 53 , no. 5 , pp. $1754-1759$.

http://pubs.acs.org/doi/ipdf/10.1021/ie4022489

11. Arutyunov, V.S., Savchenko, V.I., Sedov, I.V., Fokin, I.G., Nikitin, A.V., and Strekova, L.N., Chem. Eng. J., 2015, vol. 282, pp. 206-212. https://doi.org/10.1016/j.cej.2015.02.082

12. Al-Sayari, S.A., Open Catal. J., 2013, vol. 6, pp. 17-28. https://doi.org/10.2174/1876214X20130729001

13. Nematollahi, B., Rezaei, M., Lay, E.N., and Khajenoori, M., J. Nat. Gas Chem., 2012, vol. 21, pp. 694-702. https://doi.org/10.1016/S1003-9953(11)60421-0

14. Savchenko, V.I., Nikitin, A.V., Sedov, I.V., Ozerskii, A.V., and Arutyunov, V.S., Chem. Eng. Sci., 2019, vol. 207, pp. 744-751. https://doi.org/10.1016/j.ces.2019.07.012

15. Savchenko, V.I., Zimin, Ya.S., Nikitin, A.V., Sedov, I.V., and Arutyunov, V.S., J. $\mathrm{CO}_{2}$ Util., 2021, article no. 101490. https://doi.org/10.1016/j.jcou.2021.101490

16. NUI Galway. Combustion Chemistry Center. Mechanism Downloads.

http://c3.nuigalway.ie/combustionchemistrycentre/mechanismdownloads/\# (Accessed May 9, 2021)

17. Arutyunov, V.S. and Vedeneev, V.I., Russ. Chem. Rev., 1991, vol. 60, pp. 1384-1397. https://doi.org/10.1070/RC1991v060n12ABEH001154

18. Kevorkian, V., Heath, C.E., and Boudart, M., J. Phys. Chem., 1960, vol. 64, no. 8, pp. 964-968.

https://doi.org/10.1021/j100837a002

19. Arutyunov, V.S., Vedeneev, V.I., Moshikina, R.I., and Ushakov, V.A., Kinet. Katal., 1991, vol. 32, no. 2, pp. 234-240.

20. Savchenko, V.I., Zimin, Ya.S., Nikitin, A.V., Sedov, I.V., and Arutyunov, V.S., Petrol. Chem., 2021, vol. 61, no. 7, pp. 762-772. https://doi.org/10.1134/S0965544121070021

21. Ruscic, B., J. Phys. Chem. A, 2015, vol. 119, no. 28, pp. 7810-7837.

https://doi.org/10.1021/acs.jpca.5b01346 